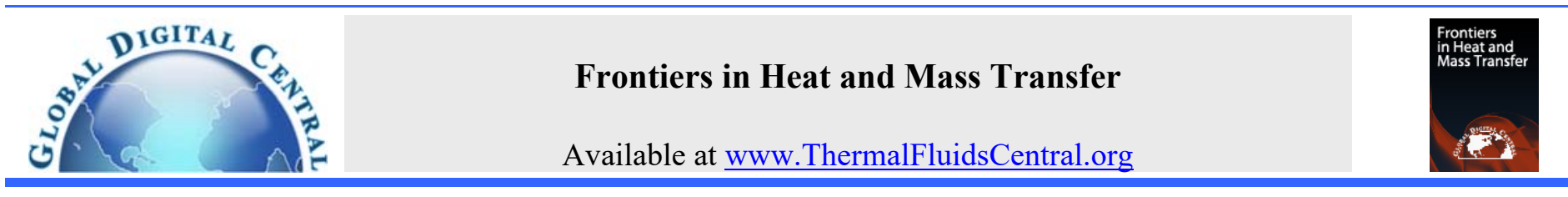

\title{
HEAT TRANSFER DETERIORATION EFFECTS OF CRYOGENIC METHANE IN ROCKET ENGINE COOLING CHANNELS
}

\author{
M. Arun ${ }^{\mathrm{a}, *}$ M. Jose Prakash ${ }^{\mathrm{b}}$ \\ ${ }^{a}$ University of Kerala, Thiruvananthapuram, Kerala, 695034, India \\ ${ }^{\mathrm{b}}$ Dept. of Mechanical Engineering, TKM College of engineering, Kollam, Kerala, 691005, India
}

\begin{abstract}
Prediction of heat transfer deterioration in rocket engine coolant channels with supercritical flow is essential while designing high pressure rocket engines. Three-dimensional conjugate heat transfer of cryogenic methane in rectangular engine cooling channels at supercritical pressures with asymmetric heating imposed on the bottom channel surface is numerically investigated, focusing on the effects of key parameters such as aspect ratio, heat flux and coolant pressure. Due to the similarity of the coolant channel with that of an actual rocket engine, the results obtained herein are beneficial for the design and optimization of rocket engine cooling systems. Heat flux is varied from $1 \mathrm{MW} / \mathrm{m}^{2}$ to $5 \mathrm{MW} / \mathrm{m}^{2}$ and the coolant pressure from $6 \mathrm{MPa}$ to $12 \mathrm{MPa}$. Results indicate that the aspect ratio has significant effect on the conjugate heat transfer owing to heat flux re-distribution in the walls. From the heat transfer point of view, channels with high aspect ratio perform well. Heat transfer deterioration is observed due to the drastic property variation near pseudocritical temperature in the region close to the wall. Increasing the operating pressure would result in improved heat transfer at supercritical pressures, particularly under high wall heat fluxes.
\end{abstract}

Keywords: Rocket cooling; Aspect Ratio; Supercritical flow: Pseudo critical; Volumetric Heat Capacity.

\section{INTRODUCTION}

Regenerative cooling is the most commonly used cooling technique for Liquid Rocket Engine (LRE) thrust chambers. Majority of the Liquid Propellant Rocket Engines (LPRE) uses fuel as the coolant, which is circulated through the narrow rectangular cooling channels to cool the thrust chamber wall. The fuel which flows through the channel reaches the injector face, from where it is injected to the combustion chamber at a pressure higher than the chamber pressure. In high pressure rocket engines a small quantity of fuel is injected through small orifices as film coolant to protect the combustion chamber wall from localized heating. Generally in regenerative coolant channels the coolant enters the channels at liquid state at supercritical pressures. Once coolant flows through the channel it will absorb the heat energy of the combustion products and transforms to supercritical fluid. Supercritical fluids are having liquid like densities and gas like diffusivities. Coolants, whose temperature below the critical temperature, and existing at or above critical pressure are refereed to be existing in transcritical state. Once the fluid transforms from transcritical state to supercritical state there is drastic variation in its thermophysical properties, especially in constant pressure specific heat and density. During transcritical to supercritical transformation the constant pressure specific heat rises up to a peak value and then decreases. The temperature at which specific heat reaches its maximum is referred as "pseudo-critical temperature". Once the coolant temperature exceeds the pseudo-critical temperature heat transfer deterioration starts.

Nowadays methane is considered as an alternative fuel for rocket engine applications. It is abundant in the outer solar system and can be harvested from Mars, Titan, Jupiter, and many other planets and moons. With fuel waiting at the destination, a rocket leaving Earth wouldn't have to carry so much propellant, reducing the cost of a mission. Further the properties of cryogenic methane like higher density, higher vaporization temperature, less challenging storage requirements compared to cryogenic hydrogen and its higher specific impulse, superior cooling capability, higher coking limit compared to kerosene created a renewed interest on space scientists in choosing methane as a propellant. The earlier studies on supercritical heat transfer phenomena were mainly focused on fluids like water (Yamagata et al., 1972; Koshizuka et al., 1995; Lee et al., 1996) and carbon dioxide (Liao and Zhao, 2002; Jiang et al., 2004; He et al., 2005) because of their industrial applications in the field of steam boilers, nuclear reactors and in refrigeration and air conditioning industries. Carlile and Quentmeyr (1992) conducted experimental studies on hydrogen to see the effect of aspect ratio on hot gas side wall temperature. They presented the results for a straight channel with gaseous hydrogen as the coolant and showed that channels with high aspect ratio have less fatigue damage. Woschnak et al. (2003) developed a new solution strategy, called quasi 2-D approach which takes into account thermal stratification and thermal diffusion effects normal to the main flow direction. Pizzarelli et al. (2007, 2008, 2009a, 2009b, 2010, 2011, 2012, 2013a, 2013b, 2014, 2015) conducted numerical studies to predict coolant flow and heat transfer deterioration in coolant channels with cryogenic methane as the fluid. They studied the effect of aspect ratio on the wall temperature and wall heat flux distribution under transcritical conditions. Pizzarelli (2016) proposed a Nusselt number correlation for convective heat transfer coefficient of supercritical flow exhibiting deterioration. Urbano et al. (2009) suggested that transcritical fluids undergo large changes in properties in little spaces, both in axial and radial directions of the channel. They reported that in addition to the semi empirical correlations available in literature, some other parametric studies are necessary so as to understand the sensitivity of wall temperature peak. A numerical study

*Corresponding author. Email: arun.m@tkmce.ac.in 
on forced convective heat transfer of $n$-heptane was done by Hua et al. (2010). Their studies reveal that supercritical heat transfer correlations for carbon dioxide and water can generally be employed for predicting the supercritical heat transfer coefficient of n-heptane when the inlet velocity exceeds $10 \mathrm{~m} / \mathrm{s}$. A modified heat transfer correlation which is applicable to the supercritical heat transfer of cryogenic methane flowing inside a horizontal mini tube with constant wall heat flux was proposed by Wang et al. (2010). Urbano and Nasuti $(2012,2013)$ analysed the heat transfer capabilities of methane by a parabolized Navier-Stokes solver which includes an accurate equation of state as well as property models, able to describe methane in all thermodynamic states of interest. Ruan and Meng (2012) conducted three dimensional numerical analyses for turbulent supercritical heat transfer of cryogenic propellant methane flowing inside a rectangular engine cooling channel with asymmetric heating on the top surface of the channel. Their studies do not consider the wall thickness of the coolant channel and the results illustrated that heat transfer deterioration phenomena could occur during a supercritical heat transfer process owing to property variation anomaly near the pseudocritical temperature. The study on rectangular channels was extended by Wang et al. (2013) considering the thickness of the wall and the reported that the thermal conductivity of the wall has significant effect on the conjugate heat transfer due to heat flux redistribution in the solid region. Trejo et al. $(2013,2014)$ experimentally investigated the heat transfer characteristics of liquid methane flowing in channels of square and rectangular cross sections and their results are in good agreement with that obtained from NASA/Rocket dyne Nusselt number correlation. Gu et al. (2013) experimentally investigated heat transfer characteristics of supercritical cryogenic methane in a miniature tube and developed a semi-empirical correlation. Their model is able to capture the $85 \%$ of experimental data within the permissible error limits. Votta et al. (2016) conducted experimental studies and proposed a correlation for determining the Nusselt number, which is valid for asymmetrically heated rectangular channels. The properties of methane at different supercritical pressures have been reported by Younglove and Ely (1987).

In the present study the conjugate heat transfer of cryogenic methane flowing in a rocket engine cooling channel at supercritical pressure with asymmetrical heating imposed on the bottom surface is considered. Due to the similarity of the coolant channel with that of an actual rocket engine, the results obtained herein are beneficial for the design and optimization of rocket engine cooling systems. The multidimensional heat conduction in the engine wall is analyzed using the fin effect. The rocket engine inner wall is usually made of alloys of copper which is having high thermal conductivity. The variation of thermal conductivity of the channel wall material with temperature is considered. Studies have been conducted to see the effect of key parameters such as Aspect Ratio (AR), wall heat flux and channel pressure on the heat transfer and wall temperature distribution. The deterioration effects are analyzed by imposing different wall heat fluxes at the hot gas side of the coolant channel referred as "heated wall"..

\section{THEORETICAL FORMULATION AND NUMERICAL APPROACH}

Generally rocket engine cooling channel dimensions are in the order of $\mathrm{mm}$. In the present study the coolant channel of a subscale rocket engine thrust chamber (Jose Prakash et al., 2012) is considered. The geometry of the computational domains and the boundary conditions are illustrated in Fig. 1. A detailed discussion on the geometry with boundary conditions is given in the next section.

The following conservation equations of mass, momentum and energy are numerically solved in the fluid phase

$\nabla .(\rho \boldsymbol{u})=0$

$\nabla .(\rho \boldsymbol{u u})=-\nabla p+\nabla \cdot \tau_{e f f}$

$\nabla \cdot\left(\rho \boldsymbol{u} e_{t}\right)=\nabla \cdot\left(\lambda_{e f f} \nabla T\right)-\nabla \cdot(p \boldsymbol{u})$

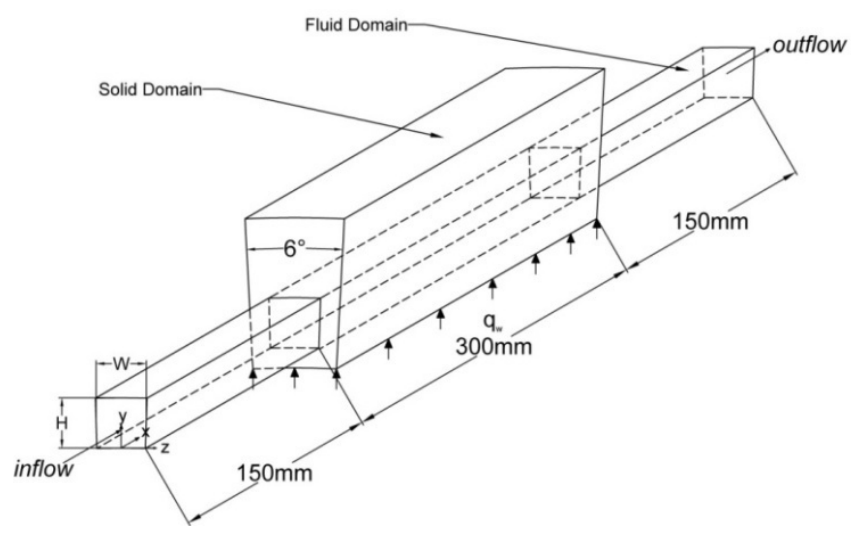

Fig. 1 Geometry of the cooling channel

In the energy conservation equation, the viscous heating term has been neglected because of low flow velocities. Standard k- $\varepsilon$ turbulent model with an enhanced wall treatment available with ANSYS Fluent (2012) is used for treating turbulent flow. The thermal conductivity equation used in the solid domain Eq. (4) is coupled with the energy transport equation in the fluid domain through the interface boundary condition; which assigns same heat flux at the boundary of solid domain and fluid domain inside the coolant channel.

$\nabla .(\lambda \nabla T)=0$

The key issue in solving fluid flow and heat transfer problems at supercritical pressures is the precise calculation of thermophysical properties, which depends on both temperature and pressure. The thermodynamic properties of methane are given in Table 1.

Table 1 Thermodynamic Parameters of Methane

\begin{tabular}{|l|c|}
\hline \multicolumn{1}{|c|}{ Parameters } & Values \\
\hline Mol. Wt.( g/mol) & 16.04 \\
\hline Critical Temperature (K) & 190.4 \\
\hline Critical Pressure $(\mathrm{MPa})$ & 4.6 \\
\hline Critical Volume $\left(\mathrm{cm}^{3} / \mathrm{mol}\right)$ & 99.2 \\
\hline Critical Compressibility factor & 0.288 \\
\hline Accentric factor & 0.011 \\
\hline
\end{tabular}

For the present study the values of density, heat capacity, viscosity and thermal conductivity of cryogenic methane are taken from the National Institute of Standards and Technology NIST data base (2005) and are incorporated into the numerical simulation (through interpolation functions) as User Defined Functions(UDF). NIST data for the properties namely density and heat capacity at different operating pressures are shown in Fig. 2. As the pressure increases the peak value of specific heat reduces, but the pseudo-critical temperature increases. The pseudo-critical temperature for $6 \mathrm{MPa}$ is $200 \mathrm{~K}$ and that for 8,10 and $12 \mathrm{MPa}$ are 210,218 and $232 \mathrm{~K}$ respectively. Since the pressure in the chamber is well above the critical conditions there is no vaporisation, but the density increases with operating pressure

\section{Modelling and Simulation}

The inner and outer radii of the combustion chamber are $47.8 \mathrm{~mm}$ $56.8 \mathrm{~mm}$ respectively. The number of coolant channels is fixed as 60 . Due to the geometrical symmetry of the combustion chamber a sectoral portion of 60 degree is chosen for the as the computational domain. The details of the geometry considered are illustrated in Fig. 3. The wall material selected is copper. 

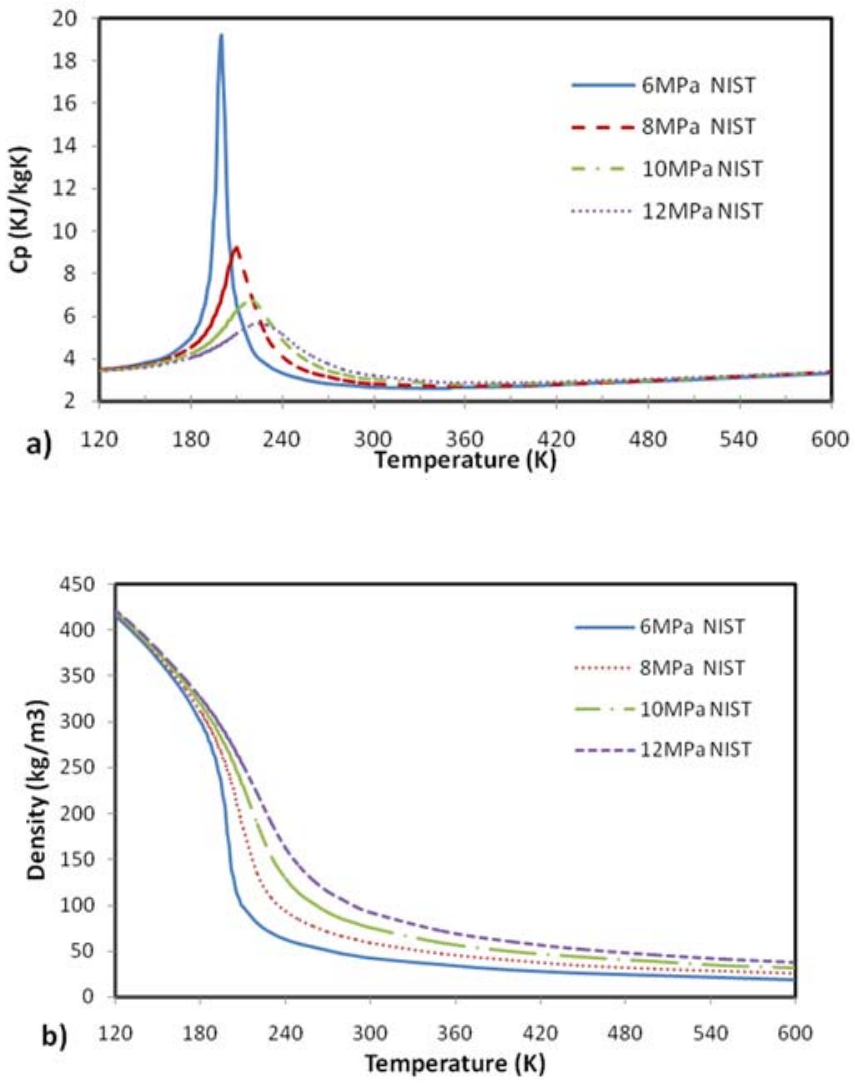

Fig. 2 Thermophysical properties of methane with temperature a) Specific heat capacity b) density

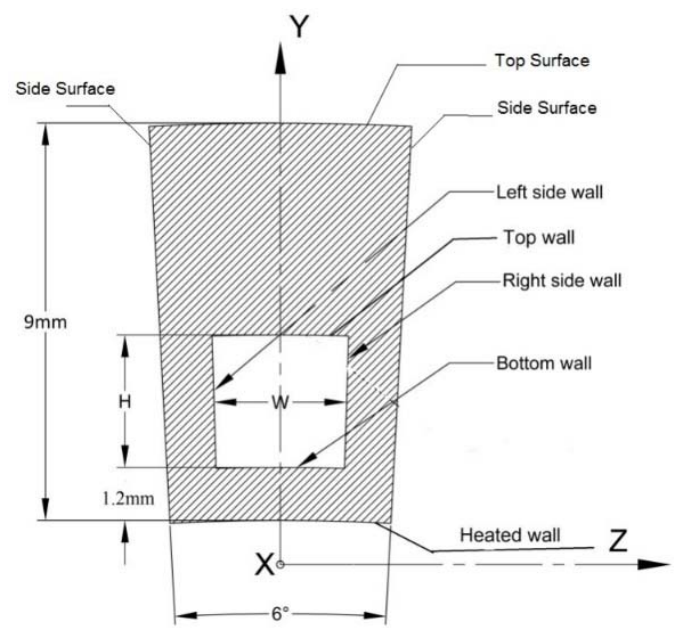

Fig.3 Dimensions of Channel Cross-Section

In order to study the effect of Aspect Ratio (AR) on the heat transfer characteristics five cases have been considered. The details are shown in Fig. 4 and table 2.

In all cases the combustion chamber wall thickness is fixed as 9 $\mathrm{mm}$, the wall thickness at the bottom of the coolant channel as $1.2 \mathrm{~mm}$ and channel cross-sectional area (A) as $9 \mathrm{~mm}^{2}$. The five different aspect ratios are obtained by varying channel height $(\mathrm{H})$ and width $(\mathrm{W})$. An entry length of $150 \mathrm{~mm}$ is provided to obtain a fully developed flow as shown in Fig.1. The exit section is provided with $150 \mathrm{~mm}$ length to avoid the outlet boundary condition effect on the accuracy of the heat transfer calculations. The test section which is $300 \mathrm{~mm}$ in length is asymmetrically heated at the bottom surface of the solid part which is referred as heated wall. The top surface of the coolant channel is assumed to be adiabatic and symmetry boundary conditions are applied at the side surfaces of the coolant channel. The inlet velocity and temperature are taken as $15 \mathrm{~m} / \mathrm{s}$ and $120 \mathrm{~K}$ respectively.

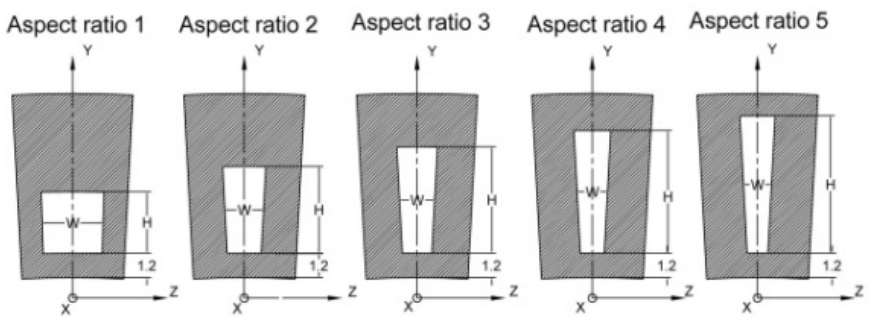

Fig. 4 Channel cross sections with different AR

Table 2 Dimensions of the flow area at various Aspect Ratios

\begin{tabular}{|c|c|c|}
\hline Aspect Ratio & $H$ & $W$ \\
\hline 1 & 3 & 3 \\
\hline 2 & $3 \sqrt{2}$ & $3 / \sqrt{2}$ \\
\hline 3 & $3 \sqrt{3}$ & $\sqrt{3}$ \\
\hline 4 & 6 & $3 / 2$ \\
\hline 5 & $3 \sqrt{5}$ & $3 / \sqrt{5}$ \\
\hline
\end{tabular}

In the case of actual rocket engine coolant channels Reynolds number is high in the order of $10^{7}$. At high Reynolds number a very thin boundary layers is formed at the walls. In order to capture the flow pattern at this condition very fine meshes are required, which requires more computational time. For the present analysis Reynolds number in the channel is in the order of $10^{5}$.

Grid independence studies have been conducted before the detailed numerical analysis. Grid system having an element size of $4 \times 10^{-04} \mathrm{~m}$ is found sufficient to produce reliable numerical results. The boundary layer resolution near the walls is optimized by using the inflation option available with ANSYS Meshing (2012). Since k- $\varepsilon$ turbulent model with an enhanced wall treatment has been used, care is taken to keep the $y+$ values $\leq 1$ for all the fluid and solid interfaces. This will help in capturing the sharp temperature gradient in the near wall region. Patch conforming tetrahedral elements are used for the domain preparation. The details of grids are represented in Fig. 5

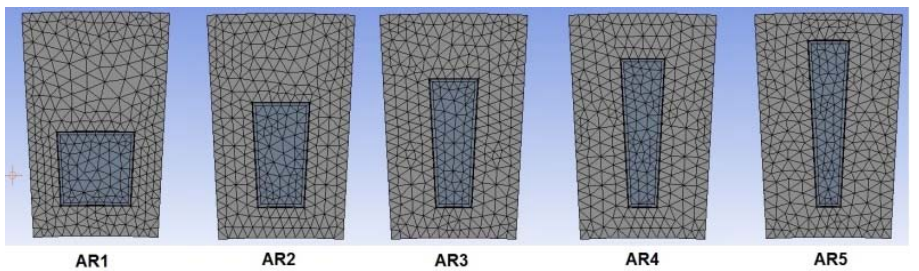

Fig. 5 Mesh Generated

\section{Results and Discussion}

The validation of the numerical scheme is carried out by comparing the results with the experimental results reported in literature ( $\mathrm{Gu}$ et al., 2013). The test section considered is a Stainless Steel (1Cr18Ni9Ti) circular tube having an inner diameter of $2.6 \mathrm{~mm}$ and wall thickness 0.5 $\mathrm{mm}$. The length of the test section is $200 \mathrm{~mm}$. The test section is imposed with heat fluxes of 4,5 and $6.5 \mathrm{MW} / \mathrm{m}^{2}$.

Figure 6 shows the results obtained from experiments and present numerical studies for supercritical heat transfer of cryogenic methane. The computed values show good agreement with the experimental results with a maximum difference of $10 \%$. 


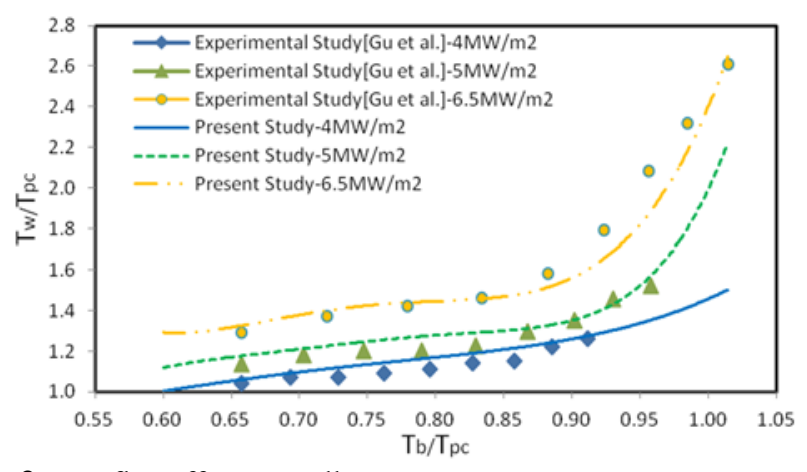

Fig. 6 Heat flux effect on wall temperatures

\subsection{Effects of Wall Heat Flux}

Generally in regenerative coolant channels the hot gas side of chamber wall is subjected to very high wall heat fluxes in the range of 0.5 to 7 $\mathrm{MW} / \mathrm{m}^{2}$. In actual rocket engine coolant channels, the walls are subjected to varying heat fluxes. Under the influence of this varying heat flux, heat transfer deterioration can occur for cryogenic methane once it transforms to supercritical state. Hence a thorough investigation is required on the effects of wall heat flux on wall temperature to predict the fundamental heat transfer characteristics of the cryogenic methane and to understand the underlying physics involved. The heated wall of the coolant channel is subjected to constant heat fluxes of 1,3 and $5 \mathrm{MW} / \mathrm{m}^{2}$.

Figure. 7 shows the variation in average heat flux at the bottom wall with aspect ratio. As the aspect ratio increases the bottom wall heat flux reduces and this is a clear indication of heat flux redistribution. When the aspect ratio is increased from 1 to 5 the percentage reduction in bottom wall heat flux are 37,34 and $39 \%$ for 1,3 and $5 \mathrm{MW} / \mathrm{m}^{2}$ respectively. This reduction is due to the increase in side wall thickness and the fin effect.

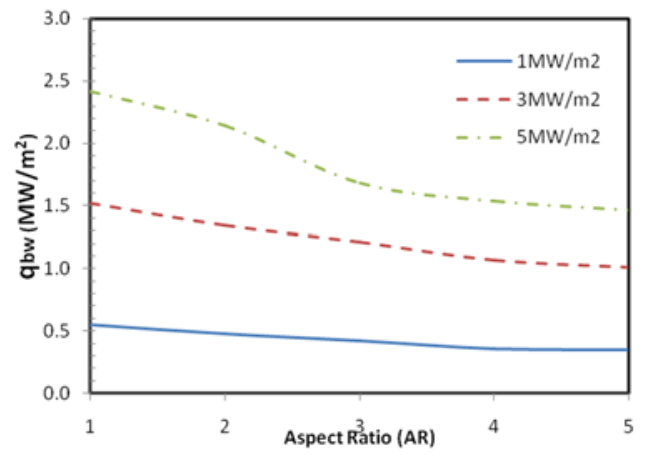

Fig. 7 Variation of Bottom wall heat flux with aspect ratio

Figure 8 shows the variation of heat transfer rate from the bottom, side and top walls with aspect ratio for the imposed heat fluxes. For all heat fluxes the heat transfer rate from the bottom and top wall decreases with aspect ratio, however a reverse trend is observed for side wall. In the case of $1 \mathrm{MW} / \mathrm{m}^{2}$ for an aspect ratio $1,30 \%$ of the total heat input is transferred to the fluid through the bottom wall and the corresponding values for 3 and $5 \mathrm{MW} / \mathrm{m}^{2}$ are $28 \%$ and $26 \%$ respectively. The reason for high heat transfer at low heat flux i.e. $1 \mathrm{MW} / \mathrm{m}^{2}$ is the high heat carrying capacity due to better volumetric heat capacity of methane. For aspect ratio 5, the decrease in heat transfer rate is marginal for all the heat fluxes. As the aspect ratio increases side wall thickness increases which in turn improves the heat flow through the side wall. With a heat flux of 1,3 and $5 \mathrm{MW} / \mathrm{m}^{2}$ the percentage of heat input from the side wall increases from 24 to $43 \%$ as the aspect ratio is increased from 1 to 5 . Heat transfer rate through the top wall decreases with increase in aspect ratio.

In the case of $1 \mathrm{MW} / \mathrm{m}^{2}$ for an aspect ratio $1,20 \%$ of the total heat input is transferred to the fluid through the top wall and the corresponding values for 3 and $5 \mathrm{MW} / \mathrm{m}^{2}$ are $21 \%$ and $24 \%$ respectively. For aspect ratio 5 the decrease in heat transfer rate is marginal for all the heat fluxes.
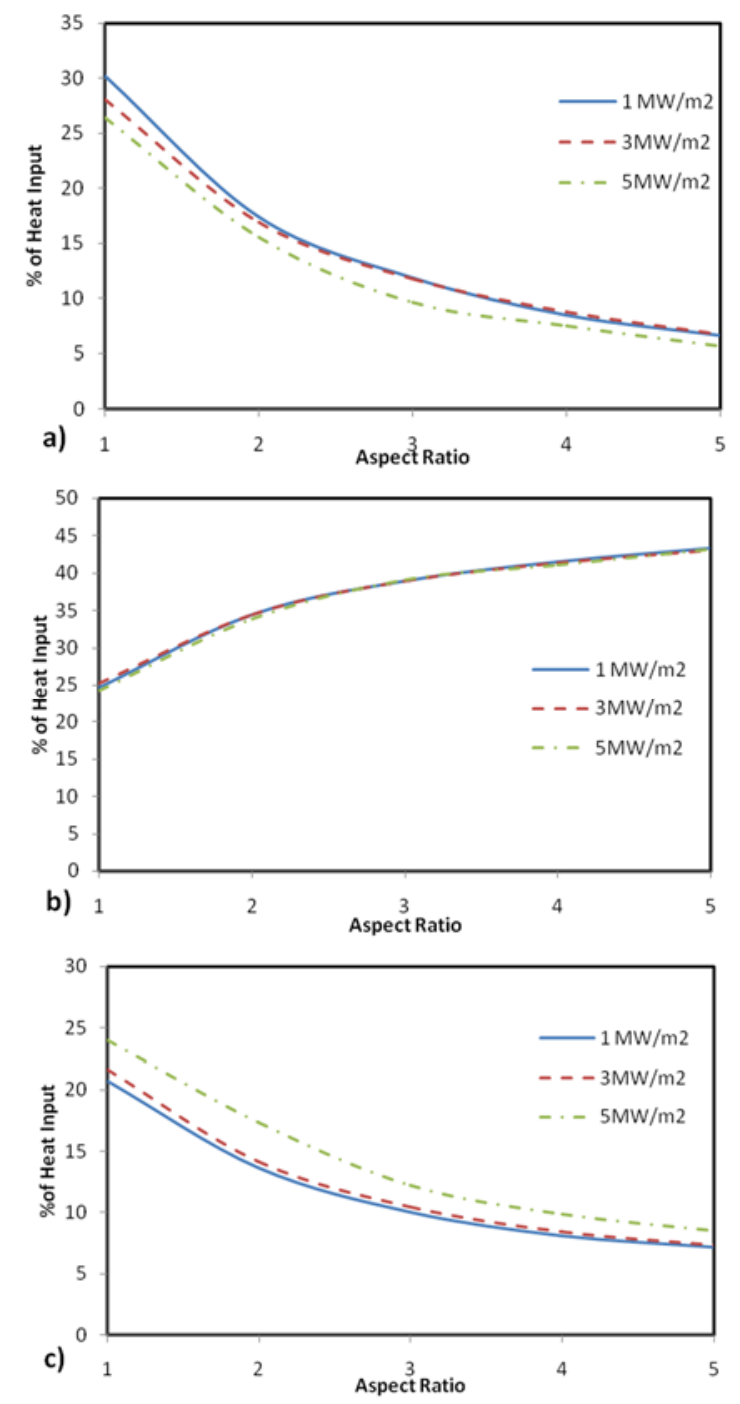

Fig. 8 Comparison of heat input through different walls a) bottom wall b) side wall c) top wall

\subsection{Volumetric Heat Capacity}

Volumetric heat capacity, the product of density and constant pressure specific heat is a measure of heat absorbing capability of the coolant. Figure 9 shows the variation of volumetric heat capacity of methane with temperature. In supercritical flows the property variations are maximum at pressures nearer to critical value. Once the operating pressure increases the property variations will decrease and this will have a profound effect on wall temperature. Generally fluids have good heat absorbing capabilities as it flows at a temperature below the critical value. Once it crosses the critical value the capability starts deteriorating leading to rise in wall temperature. The volumetric heat capacity increases up to pseudocritical point and then shows a sharp reduction. The analysis is carried out in the pressure range of $6-12 \mathrm{MPa}$. The volumetric heat capacity is maximum for $6 \mathrm{MPa}$ pressure and minimum for $12 \mathrm{MPa}$. Once the fluid crosses the critical limit the reverse of the above phenomenon happens. The variations in properties at the supercritical state will produce significant effects on supercritical heat transfer process. Generally in rocket engines, coolant channel walls are subjected to very high heat fluxes which may affect the heat absorbing capacity of the cryogenic methane. In order to predict the heat transfer deterioration with heat flux, the heated wall of the coolant channel is imposed with heat fluxes of 1 , 3 and $5 \mathrm{MW} / \mathrm{m}^{2}$. The operating pressure inside the channel is fixed as 6 $\mathrm{MPa}$. 


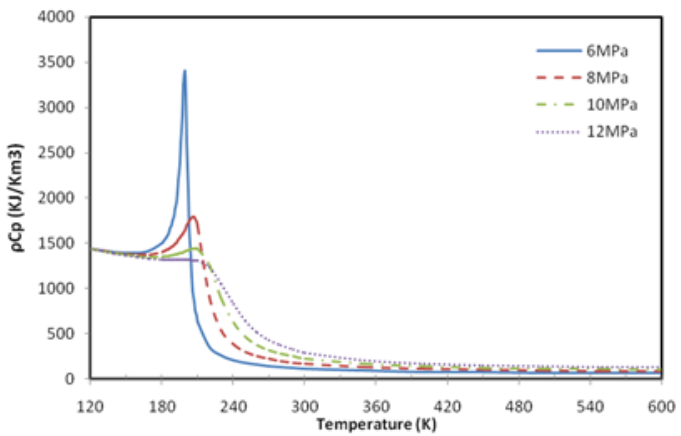

Fig. 9 Variation in volumetric heat capacity with temperature (NIST)
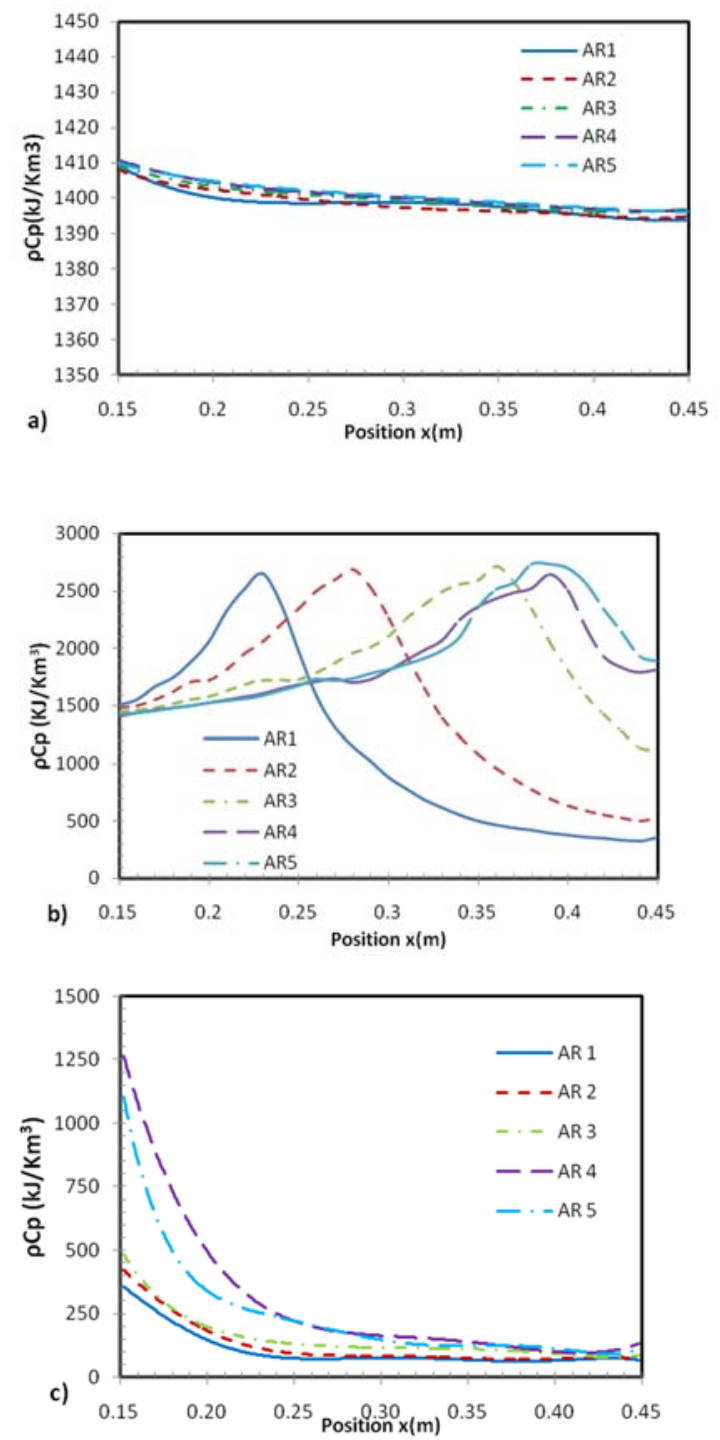

Fig. 10 Variation in volumetric heat capacity with Aspect Ratio a) $1 \mathrm{MW} / \mathrm{m}^{2}$ b) $3 \mathrm{MW} / \mathrm{m}^{2}$ c) $5 \mathrm{MW} / \mathrm{m}^{2}$

. Figure 10 shows the volumetric heat capacity of coolant at the bottom wall of the chamber for different heat fluxes

For the heat flux of $1 \mathrm{MW} / \mathrm{m}^{2}$ a reduction in volumetric heat capacity is observed along the flow direction for all the five aspect ratios. The average value of volumetric heat capacity for all aspect ratios is approximately $1400 \mathrm{~kJ} / \mathrm{Km}^{3}$. This indicates that for a heat flux of $1 \mathrm{MW} / \mathrm{m}^{2}$ the coolant layer near the bottom remains at transcritical state and the average bottom wall temperature lies in the range of $142-145 \mathrm{~K}$.
At this condition the cryogenic methane will not undergo transcritical to supercritical transformation. For the heat flux of $3 \mathrm{MW} / \mathrm{m}^{2}$ the transcritical to supercritical transformation is clearly visible. As aspect ratio increases, location of the peak value of volumetric heat capacity shifts towards the downstream and it narrows down at higher aspect ratios. The average value volumetric heat capacity increases with aspect ratio. For aspect ratio 1 the value is $1135 \mathrm{~kJ} / \mathrm{Km}^{3}$ and for aspect ratio 5 it is $1933 \mathrm{~kJ} / \mathrm{Km}^{3}$. For the heat flux of $5 \mathrm{MW} / \mathrm{m}^{2}$, a decreasing tendency in volumetric heat capacity is observed for all aspect ratios. The average values of volumetric heat capacity for aspect ratio 1 to 5 is 106,128 , 154,301 and $248 \mathrm{KJ} / \mathrm{m}^{3} \mathrm{~K}$ respectively. This low values indicate that the cryogenic methane at the entry itself transforms to supercritical state. Once the fluid reaches the supercritical state there is heat transfer deterioration.

\subsection{Heat Transfer Coefficient}

The heat transfer coefficient is defined as

$\mathrm{h}=\frac{q_{w}}{T_{w}-T_{b}}$

The effect of aspect ratio on the heat transfer coefficient at the bottom wall along the flow direction for different heat fluxes is illustrated in Fig.11. The heat transfer coefficient along the flow direction will generally decrease and this is mainly due to decrease in volumetric heat capacity along flow direction.
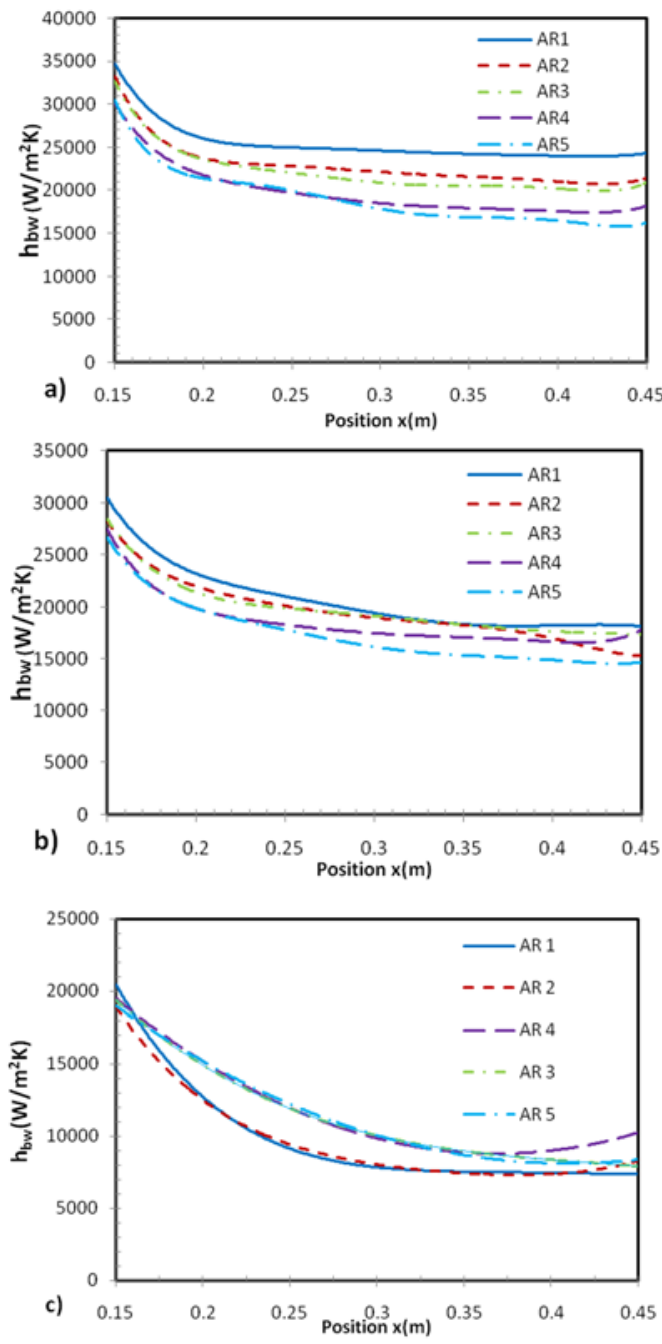

Fig. 11 Variation in heat transfer coefficients in the axial direction for various aspect ratios at bottom wall a) $1 \mathrm{MW} / \mathrm{m}^{2}$ b) $3 \mathrm{MW} / \mathrm{m}^{2}$ c) $5 \mathrm{MW} / \mathrm{m}^{2}$ 
Due to the reduction in heat carrying capacity the rise in wall temperature is faster compared to the rise in bulk fluid temperature. The variations of heat transfer coefficient with aspect ratio is illustrated in Fig. 12.

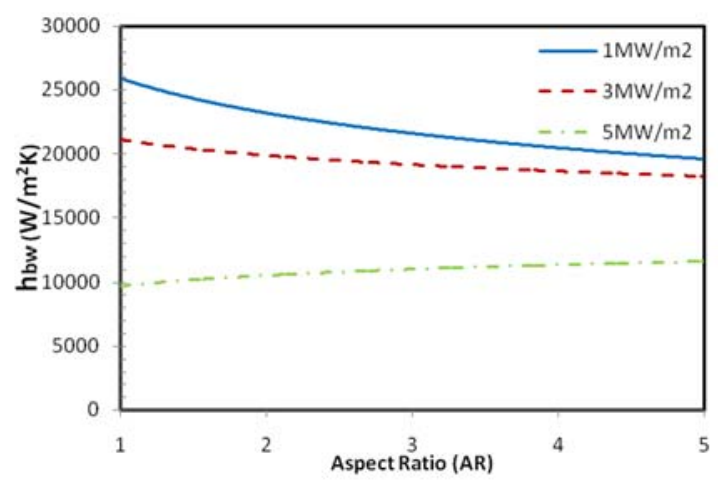

Fig. 12 Variation of wall heat transfer coefficient with aspect ratio

\subsection{Effect of Aspect Ratio on Wall Temperature}

In the present study mass flux $(\mathrm{G})$ as well as the cross sectional area of the coolant channel is kept constant. An increase in aspect ratio will result in an increase in perimeter of the channel which in turn reduces the equivalent diameter. The heat transfer coefficient is related to mass flux and equivalent diameter as

$$
\mathrm{h} \sim \frac{\mathrm{G}^{0.8}}{\mathrm{D}_{\mathrm{h}}{ }^{0.2}}
$$

For a given mass flow rate and cross sectional area, increase in aspect ratio will result in increase in heat transfer coefficient and which in turn reduces the wall temperature. Generally this prediction will lead to the conclusion that higher aspect ratio will produce better cooling than lower aspect ratio and larger pressure drop and technical difficulties in machining the narrow channel put a limit for this. But this is not true when heat fluxes are asymmetrically distributed around the channel perimeter. Once the temperature distribution is varying, nonhomogenous coolant mixing happens in the channel and thermal stratification effects will also influence the heat transfer.

The variation of the average temperature at the heated wall with aspect ratio for heat fluxes of 1,3 and $5 \mathrm{MW} / \mathrm{m}^{2}$ is shown in Fig. 13. The temperature of the heated wall for a particular aspect ratio increases in the axial direction. But as the aspect ratio increases from 1 to 5 the temperature of the heated wall decreases due to the improved heat flux redistribution caused by the reduction in thermal resistance of the wall. This helps to provide better heat transfer through the high thermal conductivity copper walls than the low thermal conductivity fluid. Also as the aspect ratio increases the fin surface area of the side wall in radial direction increases this helps to provide better heat transfer through the side walls.

It is quiet understood that as the heat flux increases the wall temperature increases. In the case of $1 \mathrm{MW} / \mathrm{m}^{2}$ for an aspect ratiol the maximum heated wall temperature is $152 \mathrm{~K}$ and average value is $148 \mathrm{~K}$. With aspect ratio 5 the corresponding values are 149 and $144 \mathrm{~K}$ respectively. The increase in heated wall temperature with aspect ratio is marginal. As discussed earlier for $1 \mathrm{MW} / \mathrm{m}^{2}$ the volumetric heat capacity at the bottom wall is approximately $1400 \mathrm{~kJ} / \mathrm{Km}^{3}$ and remains almost constant along the flow direction. In the entire flow regime fluid temperature lies well below the pseudo critical temperature. There is no heat transfer deterioration present for $1 \mathrm{MW} / \mathrm{m}^{2}$. In the case of $3 \mathrm{MW} / \mathrm{m}^{2}$ for an aspect ratiol the maximum heated wall temperature is $229 \mathrm{~K}$ and average value is $213 \mathrm{~K}$ and. With aspect ratio 5 the corresponding values are 210 and $197 \mathrm{~K}$ respectively. As mentioned earlier at $3 \mathrm{MW} / \mathrm{m}^{2}$ the volumetric heat capacity at the bottom wall increase up to a peak value and then starts decreasing. And in the flow regime near the bottom wall fluid undergoes transcritical to supercritical transformation. Here heat transfer deterioration is clearly visible for $3 \mathrm{MW} / \mathrm{m}^{2}$. In the case of $5 \mathrm{MW} / \mathrm{m}^{2}$ for aspect ratio 1 the maximum heated wall temperature is $503 \mathrm{~K}$ and average value is $421 \mathrm{~K}$ and. With aspect ratio 5 the corresponding values are 356 and $288 \mathrm{~K}$ respectively. The average value of volumetric heat capacity for aspect ratio 1 is $106 \mathrm{~kJ} / \mathrm{Km}^{3}$ and that for aspect ratio 5 is $248 \mathrm{~kJ} / \mathrm{Km}^{3}$. And in the entire flow regime near the bottom wall fluid temperature remains at supercritical state. There heat transfer deterioration is more for $5 \mathrm{MW} / \mathrm{m}^{2}$ than the other flux values under consideration.
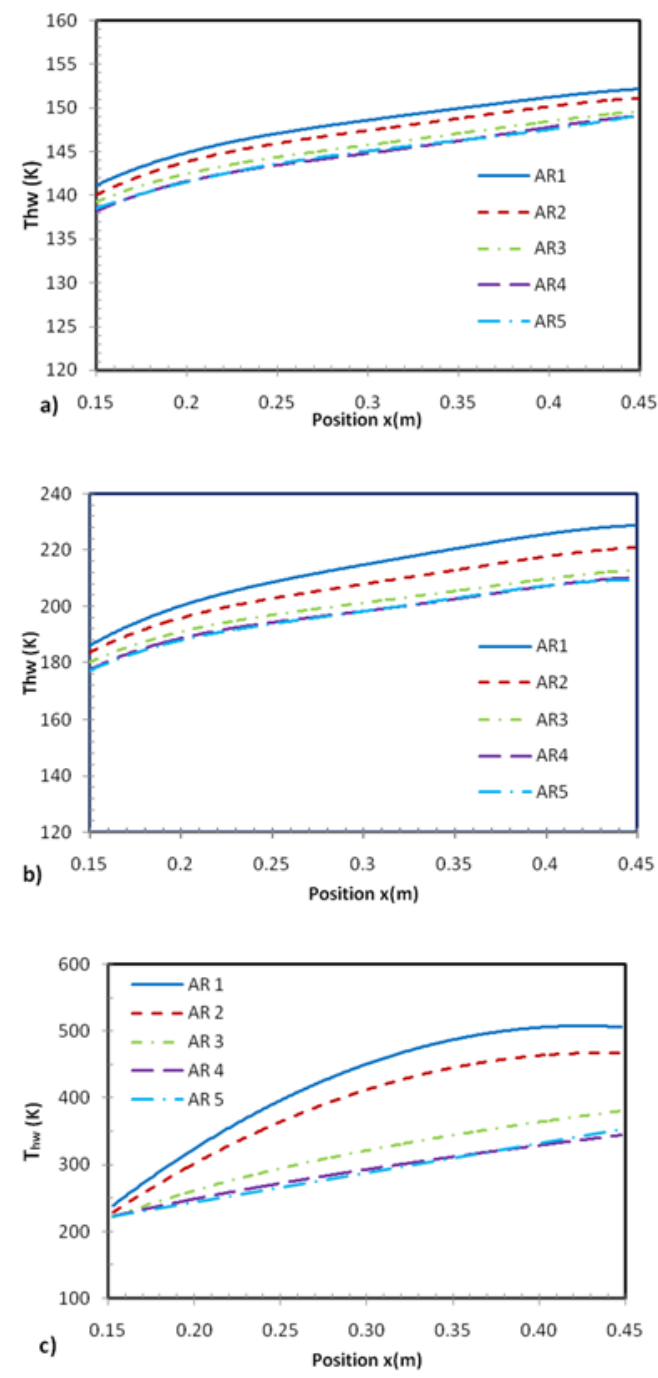

Fig. 13 Variation of average heated wall temperatures in the axial direction for different aspect ratios a) $1 \mathrm{MW} / \mathrm{m}^{2}$ b) $3 \mathrm{MW} / \mathrm{m}^{2}$ c) $5 \mathrm{MW} / \mathrm{m}^{2}$

In the case of aspect ratio 1 when the heat flux is increased from 1 $\mathrm{MW} / \mathrm{m}^{2}$ to $3 \mathrm{MW} / \mathrm{m}^{2}$, the percentage increase in average heated wall temperature is $43 \%$. But as heat flux is raised to $5 \mathrm{MW} / \mathrm{m}^{2}$ percentage increase in average heated wall temperature is $184 \%$. Low heat transfer coefficient for aspect ratio 1 at $5 \mathrm{MW} / \mathrm{m}^{2}$ is clear indication of heat transfer deterioration. As aspect ratio is raised to 5 the corresponding increment is $37 \%$ and $100 \%$. The reduction in average heated wall temperature at higher aspect ratios and high heat flux is due to the effect of density stratification. This indicates that the wall temperature not only depends on heat flux but also on the deterioration in heat transfer caused by property variation. Similar trend is observed for other walls of the channel. 

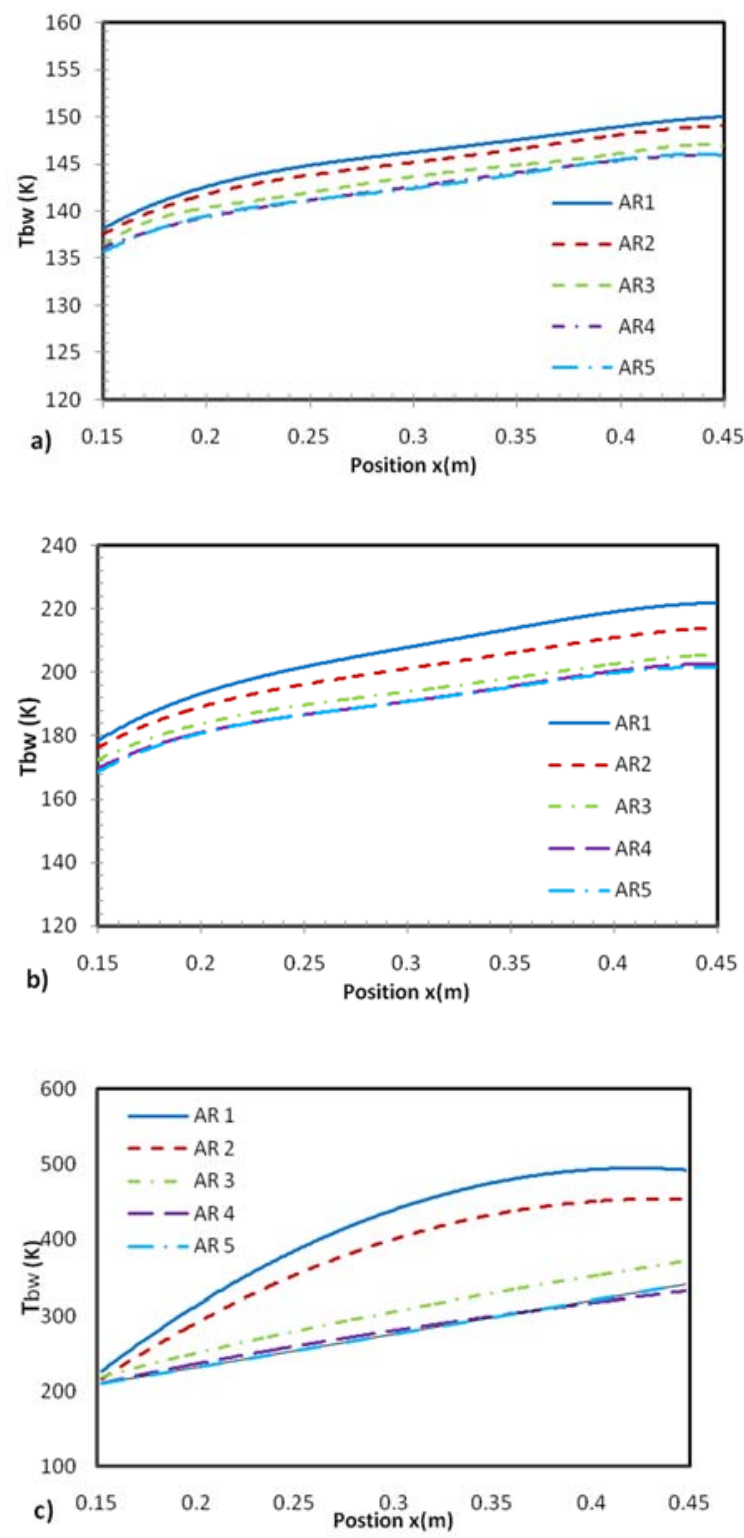

Fig. 14 Variation of average bottom wall temperatures in the axial direction for different aspect ratios a) $1 \mathrm{MW} / \mathrm{m}^{2}$ b) $3 \mathrm{MW} / \mathrm{m}^{2}$ c) $5 \mathrm{MW} / \mathrm{m}^{2}$

Figure 14 shows the variation in bottom wall temperature with aspect ratio for heat fluxes of 1,3 and $5 \mathrm{MW} / \mathrm{m}^{2}$. In the case of $1 \mathrm{MW} / \mathrm{m}^{2}$ the bottom wall temperature lies in the cryogenic temperature range. For $3 \mathrm{MW} / \mathrm{m}^{2}$ the wall temperature undergoes transcritical to supercritical transformation. In the case of $5 \mathrm{MW} / \mathrm{m}^{2}$ the wall temperature lies in the supercritical range.

Figure 15 shows the variation in side wall temperature with aspect ratio at heat fluxes of 1,3 and $5 \mathrm{MW} / \mathrm{m}^{2}$.

The wall temperature for $1 \mathrm{MW} / \mathrm{m}^{2}$ indicates that the fluid near the side wall is at cryogenic state. In the case of $3 \mathrm{MW} / \mathrm{m}^{2}$, for aspect ratio 1 the wall temperature attains the pseudo-critical temperature. For all other aspect ratios side wall temperature is below the pseudo-critical temperature. In the case of $5 \mathrm{MW} / \mathrm{m}^{2}$ the wall temperature exists in temperature corresponding to transcritical as well as supercritical states.

Figure 16 shows the variation in top wall temperature with aspect ratio at different heat fluxes of 1,3 and $5 \mathrm{MW} / \mathrm{m}^{2}$. In case of 1 and $3 \mathrm{MW} / \mathrm{m}^{2}$ it is observed that the top wall temperature is below the pseudocritical temperature. So transcritical to supercritical transformation is not visible in these cases. But in the case of $5 \mathrm{MW} / \mathrm{m}^{2}$ the fluid near the top wall undergoes transcritical to supercritical transformation which leads to heat transfer deterioration.
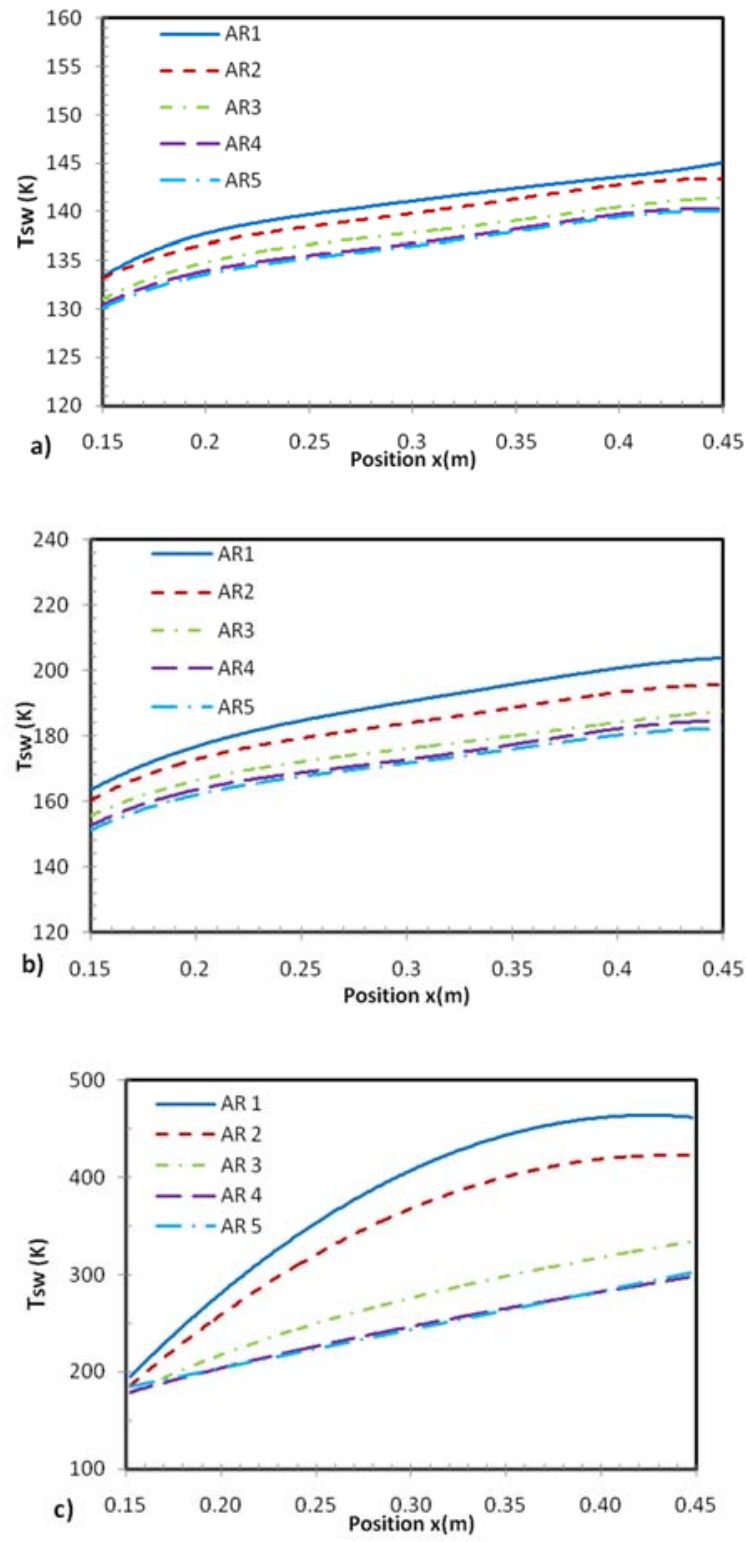

Fig. 15 Variation of average side wall temperatures in the axial direction for different aspect ratios a) $1 \mathrm{MW} / \mathrm{m}^{2}$ b) $3 \mathrm{MW} / \mathrm{m}^{2}$ c) $5 \mathrm{MW} / \mathrm{m}^{2}$

\subsection{Effect of pressure on wall temperature}

Pressure inside the coolant channel is varied for a constant wall heat flux of $5 \mathrm{MW} / \mathrm{m}^{2}$. The selected pressures are 6,8,10 and $12 \mathrm{MPa}$. Figure 17. Shows the variation of average heated wall temperatures at different coolant channel pressures.

It is observed that as the channel pressure increases the wall temperature decreases owing to the reduction in drastic property variations. As discussed earlier, beyond the critical point, at higher pressures heat carrying capacity of the coolant is high causing a reduction in wall temperature. The reduction in heated wall temperature for aspect ratio 1 as pressure is increased from $6 \mathrm{MPa}$ to $12 \mathrm{MPa}$ is $35 \%$, while that for aspect ratio 5 is $10 \%$. 

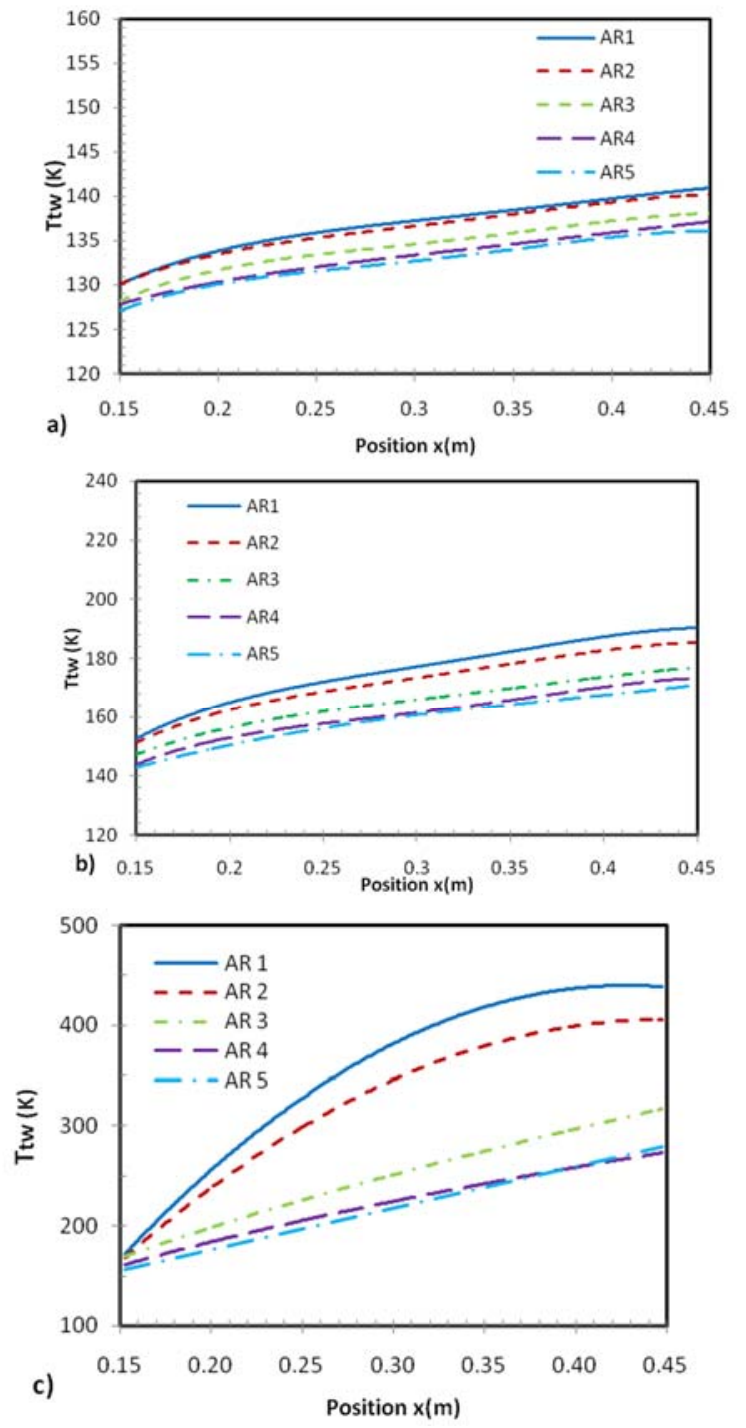

Fig. 16 Variation of average top wall temperatures in the axial direction for different aspect ratios a) $1 \mathrm{MW} / \mathrm{m}^{2}$ b) $3 \mathrm{MW} / \mathrm{m}^{2}$ c) $5 \mathrm{MW} / \mathrm{m}^{2}$
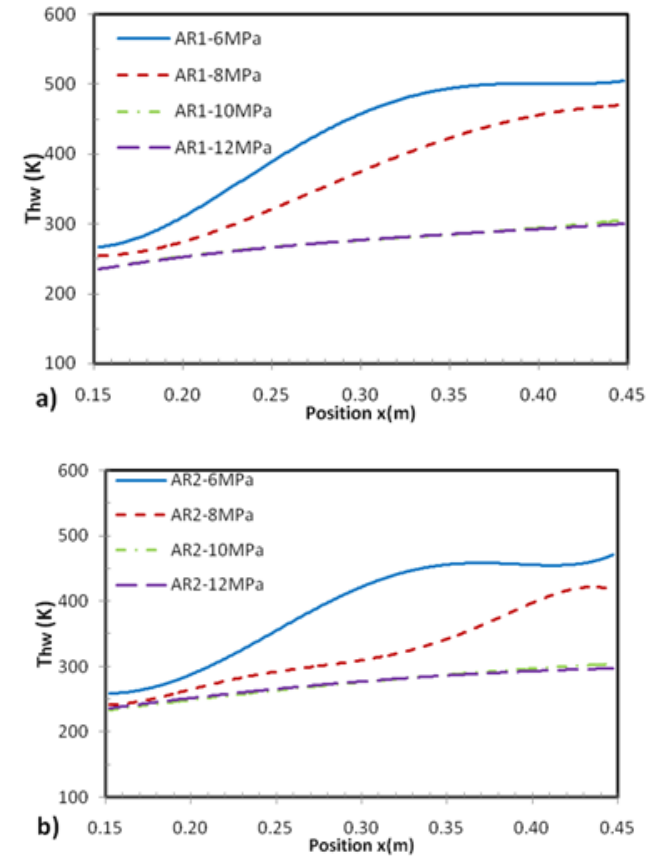
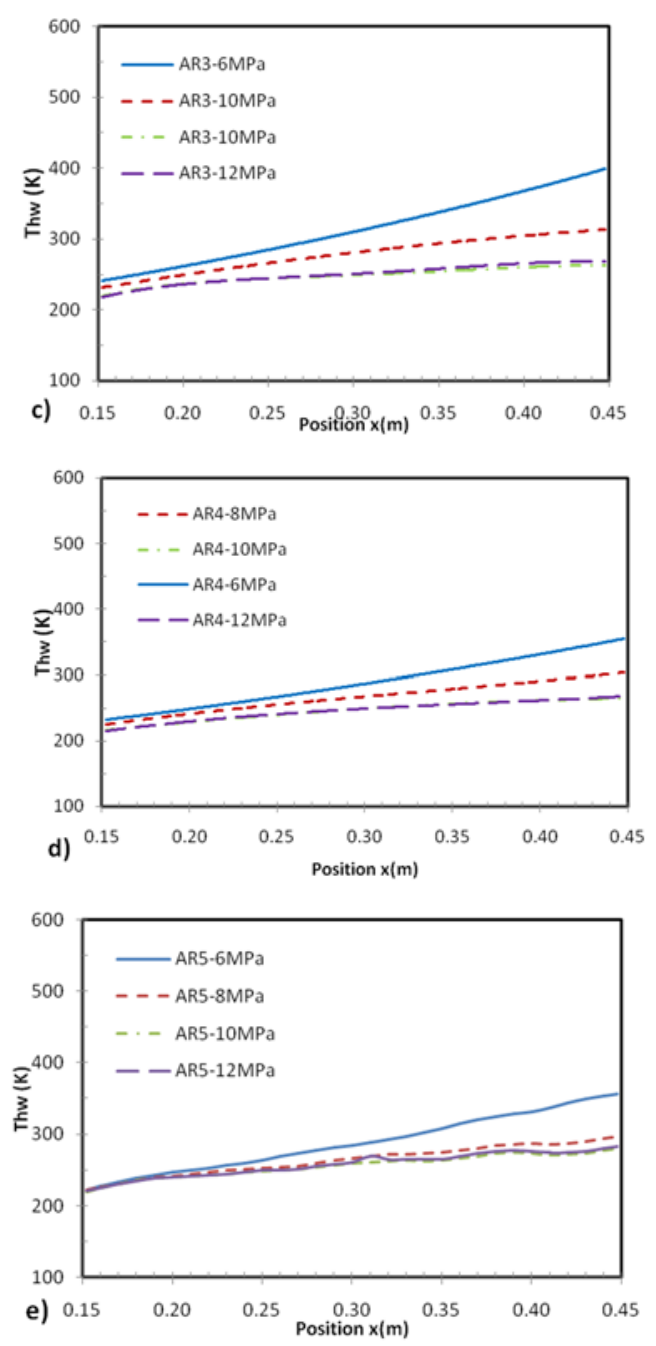

Fig. 17 Variation of average heated wall temperatures in the axial direction for different channel pressures with aspect ratio AR2 c) AR3 d) AR4 e) AR5

As observed in the previous sections, the heated wall temperature decreases with aspect ratio for a given channel pressure.

\section{Conclusions}

In this paper, three dimensional turbulent conjugate heat transfer of cryogenic methane flowing inside the cooling channel of a rocket engine is numerically investigated. Effects of key parameters such as aspect ratio, wall heat fluxes and channel pressures on wall temperature, heat transfer coefficient are studied. The present study incorporates accurate evaluation of thermal and transport properties of methane at transcritical supercritical conditions. The variation in properties of wall material with temperature is taken into account. The heat transfer deterioration of the coolant near the walls is examined. The following conclusions could be reached.

1. Aspect ratio, applied heat flux and operating pressure have significant effects on wall temperature, owing to the drastic variation in thermo physical properties of cryogenic methane at supercritical conditions.

2. Better heat flux redistribution at higher aspect ratios results in uniform temperature of the coolant

3. From the heat transfer point of view a shallow cooling channel performs well especially at high heat fluxes.

4. The optimum aspect ratio for coolant channels operating near the critical conditions depends on applied heat flux. 
5. The heat transfer deterioration is predominant at operating pressure 6 $\mathrm{MPa}$ and at high heat fluxes. Enhancing the operating pressure will alleviate chances of heat transfer deterioration.

6. Heat transfer deterioration is not present at low heat flux i.e. $1 \mathrm{MW} / \mathrm{m}^{2}$.

\section{NOMENCLATURE}

A Channel area, $\mathrm{m} 2$

C constants in turbulent model

$\mathrm{C}_{\mathrm{p}} \quad$ constant pressure heat capacity, $\mathrm{J} / \mathrm{kgK}$

D channel hydraulic diameter, $\mathrm{m}$

et total internal energy, $\mathrm{J} / \mathrm{kg}$

$\mathrm{G}$ mass flow rate per unit area, $\mathrm{kg} / \mathrm{m}^{2}$

$\mathrm{H} \quad$ channel height, $\mathrm{mm}$

h convective heat transfer coefficient, $\mathrm{W} / \mathrm{m}^{2} \mathrm{~K}$

$\mathrm{k} \quad$ turbulent kinetic energy, $\mathrm{J} / \mathrm{kg}$

$\mathrm{P} \quad$ pressure, $\mathrm{Pa}$

$q \quad$ heat flux $\mathrm{W} / \mathrm{m}^{2}$

$\mathrm{T} \quad$ Temperature, $\mathrm{K}$

u velocity vector, $\mathrm{m} / \mathrm{s}$

W channel width, $\mathrm{mm}$

$\mathrm{x}$ coordinate, $\mathrm{m}$

$\mathrm{y} \quad$ coordinate, $\mathrm{m}$

$\mathrm{z}$ coordinate, $\mathrm{m}$

\section{Greek}

$\varepsilon \quad$ turbulent dissipation rate, $\mathrm{m}^{2} / \mathrm{s}^{3}$

$\lambda$ thermal conductivity, $\mathrm{W} / \mathrm{mK}$

$\mu \quad$ viscosity, $\mathrm{kg} / \mathrm{m}$-s

$\rho \quad$ density, $\mathrm{Kg} / \mathrm{m}^{3}$

$\sigma \quad$ turbulent Prandtl number

$\tau \quad$ viscous stress, $\mathrm{N} / \mathrm{m}^{2}$

Subscripts

b bulk parameter

bw parameters at the bottom wall

eff effective parameters in turbulent flows

hw parameters at the heated wall

pc pseudo critical parameter

sw parameters at the side wall

$\mathrm{t}$ turbulent parameter

tw parameters at the top wall

w wall

\section{REFERENCES}

Carlile, J., and Quentmeyer, R., 1992, "An Experimental Investigation of High Aspect Ratio Cooling Passages," In 28th AIAA/SAE/ASME/ASEE Joint Propulsion Conference and Exhibit, Nashville, USA, AIAA 923154.

https://doi.org/10.2514/6.1992-3154

Gu,H., Li H., Wang, H., and Luo, Y.,2013, "Experimental Investigation on Convective Heat Transfer from a Horizontal miniature tube to Methane at Supercritical Pressure," Applied Thermal Engineering 58,490-498.

http://doi.org/10.1016/j.applthermaleng.2013.04.049

He, S., Jiang, P.X.,. Xu, Y.J., Shi, R.F., Kim, W.S., and Jackson, J.D., 2005," A Computational Study of Convection Heat Transfer to CO2 at Supercritical Pressures in a Vertical Mini Tube, "International Journal of Thermal Sciences 44(6), 521-530.

http://dx.doi:10.1016/j.ijthermalsci.2004.11.003

Hua, Y. X., Wang, Y. Z., and Meng, H., 2010, “A Numerical Study of Supercritical Forced Convective Heat Transfer of $n$-Heptane inside a Horizontal Miniature Tube," The Journal of Supercritical Fluids, 52(1), 36-46. http://doi:10.1016/j.supflu.2009.12.003

Jiang, P.X., Xu, Y.J., Lv, J., Shi, R.F., He, S., and Jackson J.D.,2004, "Experimental Investigation of Convection Heat Transfer of $\mathrm{CO} 2$ at Supercritical Pressures in Vertical mini tubes and in Porous media," Applied Thermal Engineering, 24, 1255-1270.

http://doi.org/10.1016/j.applthermaleng.2003.12.024

Jose Prakash, M. et al., 2012, "Numerical Studies on Combustion in a Film Cooled Semi-Cryogenic Rocket Thrust Chamber," AIAA Paper 2012- 4167, In 48 ${ }^{\text {th }}$ AIAA/SAE/ASME/ASEE Joint Propulsion Conference and Exhibit.

https://doi.org/10.2514/6.2012-4167

Koshizuka, S., Takano, N., and Oka Y., 1995, "Numerical Analysis of Deterioration Phenomena in Heat Transfer to Supercritical Water," International Journal of Heat and Mass Transfer, 38(3), 3077-3084. http://dx.doi:10.1016/0017-9310(95)00008-W

Lee, S. H., and John, R. Howell, 1996, "Laminar Forced Convection at Zero Gravity to Water near the Critical Region," Journal of Thermophysics and Heat Transferr, 10(3), 504-510. http://dx.doi:10.2514/3.817

Liao, S. M., and Zhao, T. S., 2002, “An Experimental Investigation of Convection Heat Transfer to Supercritical Carbon Dioxide in Miniature Tubes," International Journal of Heat and Mass Transfer, 45(2).50255034.

http://doi.org/10.1016/S0017-9310(02)00206-5

Pizzarelli, M., Nasuti, F., and M. Onofri, M., 2007, “A Simplified Model for the Analysis of Thermal Stratification in Cooling Channels," Session 5.02, In 2nd European Conference for Aerospace Sciences.

Pizzarelli, M., Nasuti, F., and Onofri, M., 2008, "Flow Analysis of Transcritical Methane in Rectangular Cooling Channels," In 44th AIAA/SAE/ASME/ASEE Joint Propulsion Conference and Exhibit, Hartford, CT, AIAA 2008-4556.

https://doi.org/10.2514/6.2008-4556

Pizzarelli, M., Nasuti, F., and M. Onofri, M., 2009, "Investigation of Transcritical Methane Flow and Heat Transfer in Curved Cooling Channels," In 45th AIAA/SAE/ASME/ASEE Joint Propulsion Conference and Exhibit, Denver, Colorado, AIAA 2009-5304. https://doi.org/10.2514/6.2009-5304

Pizzarelli, M., Urbano, A., Nasuti, F., and M. Onofri, M., 2009, “CFD Analysis of Heat Transfer to Transcritical Fluids in Liquid Rocket Engines," In 6th European Symposium on Aero theromodynamics for Space Vehicles, ESA SP-659.

Pizzarelli, M., Urbano, A., and Nasuti, F.,2010, "Numerical Analysis of Deterioration in Heat Transfer to Near-Critical Rocket Propellants," Numerical Heat Transfer, Part A:Applications: An International Journal of Computation and Methodology, 57(5), 297-314.

http://dx.doi.org/10.1080/10407780903583016

Pizzarelli, M., Betti, B., and Nasuti, F., 2011, "Coupled analysis of hotgas and Coolant flows in LOX/methane Thrust chambers," In $4^{\text {th }}$ European Conference for Aerospace Sciences.

Pizzarelli, M., Nasuti, F., and M. Onofri, M., 2012, "CFD analysis of Transcritical Methane in Rocket Engine Colling Channels," Journal of Supercritical Fluids, 62, 79-87.

http://doi.org/10.1016/j.supflu.2011.10.014

Pizzarelli, M., Nasuti, F., Onofri, M., Roncioni, P., Votta, R., Battista F. , 2013, "Supercritical Methane Heat Transfer Modeling in Rocket Engine Cooling Channels," In 49th AIAA/SAE/ASME/ASEE Joint Propulsion Conference, San Jose, CA, AIAA 2013-3995.

https://doi.org/10.2514/6.2013-3995 
Pizzarelli, M., Nasuti, F., and Onofri, M., 2013 "Trade-off analysis of high-aspect-ratio -cooling-channels for rocket engines," International Journal of Heat and Fluid flow, 44, 458-467. https://doi.org/10.1016/j.ijheatfluidflow.2013.08.003

Pizzarelli, M., Nasuti, F., and Onofri, M., 2014, "Effect of Cooling Channel Aspect Ratio on Rocket Thermal Behavior," Journal of Thermophysics and Heat Transfer, 28(3) 3,410-416. http://dx.doi.org/10.2514/1.T4299

Pizzarelli, M., Nasuti, F., Onofri, M., Roncioni, P., Votta, R., Battista F., 2015, "Heat Transfer Modeling for Supercritical Methane flowing in Rocket Engine Cooling Channels," Applied Thermal Engineering, 75, 600-607.

https://doi.org/10.1016/j.applthermaleng.2014.10.008

Pizzarelli, M., 2016, "A CFD Derived Correlation for Methane heat Transfer deterioration," Numerical Heat Transfer, Part A: Applications, 69(3), 242-264.

https://doi.org/10.1080/10407782.2015.1080575

Ruan B., Meng H.,2012" Supercritical heat transfer of cryogenicpropellant methane in rectangular engine cooling channels," Journal of Thermophysics and Heat Transfer, 26(2), 313-321.

https://doi.org/10.2514/1.T3670

Trejo, A., Gracia, C., Galvan, M., and Choudhuri, A., Melcher, J., Bruggemann, J., 2013, "An Experimental Investigation on the Steady State Heat Transfer Characteristics of Liquid Methane," In 49th AIAA/SAE/ASME/ASEE Joint Propulsion Conference, AIAA Paper 2013-4145.

https://doi.org/10.2514/6.2013-4145

Trejo, A., Garcia, C., Galvin, M., Choudhuri, A., 2014 "Experimental I nvestigation of Liquid Methane Convection and Boiling in Rocket Engine Cooling Channels," In 50th AIAA/SAE/ASME/ASEE Joint Propulsion Conference, AIAA 2014-4007.

https://doi.org/10.2514/6.2014-4007

Urbano, A., and Nasuti, F., 2013, "Conditions for the occurrence of Heat transfer Deterioration in Light Hydrocarbon Flows," International Journal of Heat and Mass Transfer, 65, 599-609.

https://doi.org/10.1016/j.ijheatmasstransfer.2013.06.038

Urbano, A., and Nasuti, F., 2012, "Parametric Analysis of Heat Transfer to Supercritical-Pressure Methane," Journal of Thermophysics and Heat Transfer, 26(3), 450-463.

https://doi.org/10.2514/1.T3840
Urbano, A., Pizzarelli, M., and Nasuti, F., 2009, "Numerical Analysis of Transcritical Fluids Heating in Liquid Rocket Engine Cooling Channels," The Journal of Aerospace Science Technology Systems, $\mathbf{8 8}$ (1/2), 20-30.

Votta, R., Battista, F., Salvatore, V., Pizzarelli, M., Leccese, G., Nasuti, F., and Meyer S., 2016, "Experimental Investigation of Transcritical Methane Flow in Rocket Engine Cooling Channel," Applied Thermal Engineering,48(7), 61-70.

http://dx.doi.org/10.1016/j.applthermaleng.2015.12.019

Wang L., Chen Z and Meng H., 2013, "Numerical Study of Conjugate Heat Transfer of Cryogenic Methane in Rectangular Engine Cooling Channels at Supercritical Pressures," Applied Thermal Engineering, 54, 237-246.

doi.org/10.1016/j.applthermaleng.2013.02.007

Wang, Y. Z., Hua, Y. X., and Meng, H., 2010, "Numerical Study of Supercritical Turbulent Convective Heat Transfer of Cryogenic Propellant Methane," Journal of Thermophysics and Heat Transfer, 24(3), 490-500.

https://doi.org/10.2514/1.46769

Woschnak, A., Suslovy, D., and Oschwald, M., 2003, "Experimental And Numerical Investigations of Thermal Stratification Effects," In 39th AIAA/SAE/ASME/ASEE Joint Propulsion Conference and Exhibit, Huntsville, Alabama, AIAA 2003-4615. https://doi.org/10.2514/6.2003-4615

Yamaagata, K., Nishikawa, K., Hasegawa, S., Fujii, T., and Yoshida, S., 1972, "Forced Convective Heat Transfer to Supercritical Water Flowing in Tubes," International Journal of Heat and Mass Transfer, 15, 25752593.

https://doi.org/10.1016/0017-9310(72)90148-2

Younglove, B. A., and Ely, J. F., 1987, "Thermophysical Properties of Fluids II. Methane, Ethane, Propane, Isobutane, and Normal Butane," Journal of Physical and Chemical Reference Data, 16(4) 577-796. https://doi.org/10.1063/1.555785

“Ansys Fluent 14.5 User's Guide”, Ansys, Inc., Canonsburg USA, 2012.

“Ansys Meshing 14.5 User's Guide”, Ansys, Inc., Canonsburg USA, 2012.

NIST Standard Reference Data base Number 69. 